\title{
Calculation of Parameters of Energy Flows in a Closed System of Electricity Generation based on Renewable Sources
}

\author{
Telegin Valery Viktorovich
}

\begin{abstract}
:. the article is devoted to the calculation of the generated power in Autonomous power systems based on wind power plants, photovoltaic panels, small hydroelectric power plants. The model of the designed system is considered to be closed and contains energy storage modules for accumulating part of the power. The idea of optimizing the system is based on the determination of the composition of the combined power generation complex, in which the efficiency criteria reach an extremum.
\end{abstract}

Index Terms: wind power plants; photovoltaic panels; small hydroelectric power plants.

\section{INTRODUCTION}

Modern world industry is increasingly developing and reclaiming remote regions which were not widely used previously. Energy supply of production facilities as well as residential complexes located at a considerable distance from the power grid [1 - 4]is becoming necessary. The solution to this problem is energy supply based on the use of renewable or alternative energy technologies $[5,6]$.

Revised Manuscript Received on July 09, 2019.

Telegin Valery Viktorovich, Lipetsk State Technical University, LSTU, Lipetsk, Russia

\section{STRUCTURE OF AUTONOMOUS ENERGY COMPLEX}

The autonomous power generating complex [7, 8], built on the basis of renewable energy sources, considered in this paper, is a system of three types of power generating units that convert wind energy $[9,10]$, solar radiation [11, 12] and water flow [13, 14] into electrical energy, as well as its accumulation and discharge devices $[15,16]$. The presence and quantity of each of these types of installations determines the structure of the generating set, the structural and economic characteristics - its parameters [17, 18].

\section{STATEMENT OF THE RESEARCH PROBLEM}

The efficiency of the power generating complex is determined, in general, by a whole set of values of indicators its performance, reliability, and economic plan characteristics depend on: cost, cost of electricity, payback period, as well as allocation area, serviceability and a number of other criteria $[19,20]$. Assuming that the power supply system of the autonomous consumer is closed, it can be stated that the sum of the powers of the sources of electric energy should be equal to the sum of the powers expended in receivers, minus the losses due to its transmission and various kinds of transformations. Energy sources in this system are wind energy generators (WEG), photoelectric converters (FEC) and hydropower generators (GEG). Receivers are the consumer and ballast resistance (BR). The system of electric power accumulation, depending on the generated and consumed energy quantitative ratio, can act both in the role of its source and receiver. The task of designing an autonomous electro-generating complex can naturally be formulated as the problem of finding the values of its parameters, under which the energy complex efficiency criteria reach extremes. The scope of the search for the acceptable values of these parameters must satisfy the power balance equation of the autonomous electro-generating complex under consideration, as well as the design constraints on their minimum and maximum values. The solution of this problem

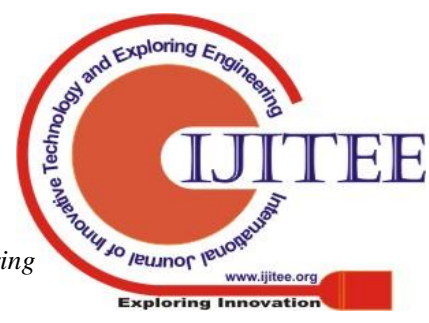


can be performed numerically on the basis of optimization and simulation methods based on modern computer technologies.

\section{CONSTRUCTION OF THE MODEL AND CALCULATION OF THE PARAMETERS OF THE ELECTRO GENERATING COMPLEX}

As a result of the research carried out by the author [20], two groups of criteria that determine the effectiveness of the energy complex: economic and energy were established. As the only economic efficiency criterion, it is logical to take the cost of generating and converting devices, including their delivery, installation and commissioning $\left(\mathrm{C}_{\Sigma}\right)$. The costs of using renewable energy sources are associated only with the maintenance of generating and accumulating devices, do not require any additional investment, for example, for the purchase and delivery of fuel. With relatively small amounts of generated electricity, such generally accepted criteria for economic efficiency, such as the annual costs per kilowatt of installed capacity and the cost of electricity, are proportional to $\mathrm{C}_{\Sigma}$.

The total cost of the equipment of an autonomous power supply system, taking into account its installation,

can be found from the expression:

$$
C_{\Sigma}=C_{w} \cdot N_{w}+C_{p} \cdot N_{p}+C_{h} \cdot N_{h}+C_{a} \cdot N_{a},
$$

where $C_{w}, C_{p}, C_{h}$ and $C_{a}$ - the cost of wind, photo, hydropower and accumulation equipment, taking into account its installation, $N_{w}, N_{p}, N_{h}$ and $N_{a}$, respectively, their number.

The values of the parameters $N_{w}, N_{p}, N_{h}$ and $N_{a}$ determine the structure of the electro generating complex, that is, the presence or absence of generating devices.

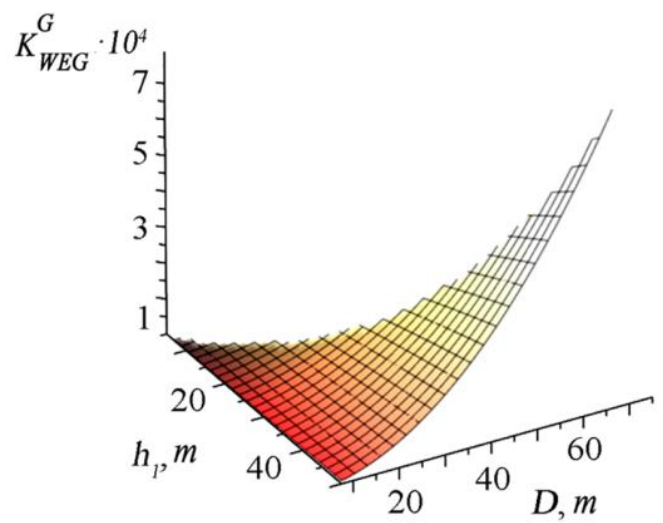

$\mathrm{a}$

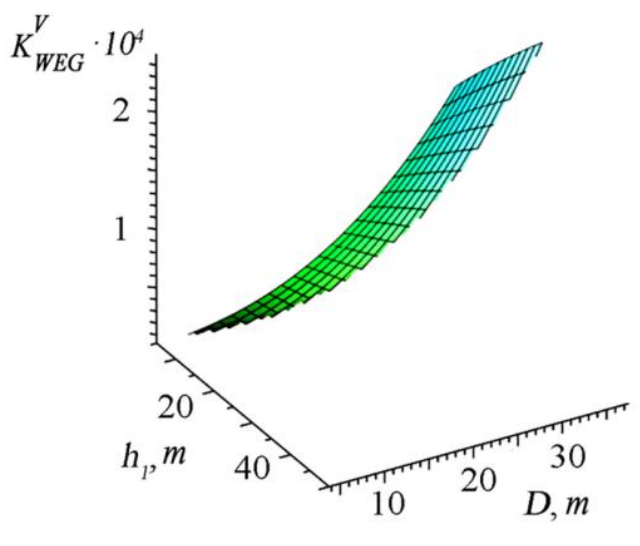

b

Figure 1: The effect of the design parameters of the wind turbine with the horizontal (a) and vertical (b) axes on its power

Between the design parameters of generating units and their power, there are dependencies. Formulas for calculating the total power of the WEG $\left(P_{\mathrm{w}}\right)$ with horizontal and vertical axes [9]:

$$
\begin{gathered}
P_{w}=\frac{\pi V_{0}^{3}}{8 h_{0}^{3 k}} \rho_{a} \cdot \eta_{W E G}^{H} \cdot \eta_{p w} \cdot K_{W E G}^{H} \cdot N_{w}, \\
P_{w}=\frac{V_{0}^{3}}{2 h_{0}^{3 k}} \rho_{a} \cdot \eta_{W E G}^{V} \cdot \eta_{p w} \cdot K_{W E G}^{V} \cdot N_{w},
\end{gathered}
$$

where $\rho_{a}$ - air density, $\mathrm{kg} / \mathrm{m}^{3} ; V_{0}$ - wind speed at the height of the weather vane, $\mathrm{m} / \mathrm{s} ; h_{0}$ - weather vane height, $\mathrm{m} ; k$ - coefficient characterizing the type of terrain and ground surface; $\eta^{H}{ }_{\text {weg }}, \quad \eta_{\text {weg }}^{V}-$ coefficient of efficiency of wind turbines with horizontal and vertical axes; $\eta_{p w}-$ efficiency coefficient of power lines, communication systems, stabilization, etc. for wind turbines.

In the formulas (2) and (3) of the functions of $K^{H}{ }_{W E G}, K^{V}{ }_{W E G}$ the coefficients connecting the design parameters of the WEG with the horizontal and vertical axes. For a WEG with a horizontal axis and a vertical axis, we will accordingly have:

$$
\begin{gathered}
K_{W E G}^{H}=D^{2} \cdot h_{1}^{3 k}, \quad h_{1} \geq 0.75 \cdot D ; \\
K_{W E G}^{V}=D \cdot H \cdot\left(h_{1}+\frac{H}{2}\right)^{3 k}, h_{1} \leq m\left(\frac{D}{H}\right) \cdot D, \\
m\left(\frac{D}{H}\right)=\frac{5}{28} \frac{D}{H}+\frac{4}{7} .
\end{gathered}
$$

The minimum height of the WEG mast $\left(h_{l}\right)$ is limited to $h_{\min }$ (5 meters), maximum - $h_{\max }$ (50 meters). Then the values of the wind wheel diameter for the WEG with the horizontal axis will vary from 7.5 to 75 , and with the vertical axis, with $D=H$, from 3.75 to 37.5 meters. The functions of $K^{H}{ }_{W E G}, K^{V}{ }_{W E G}$ presented in Figure 1, are smooth, with no apparent

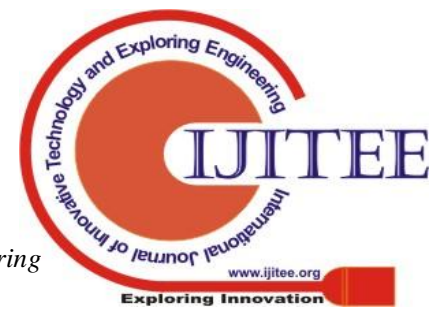


extremes. In other words, it is pointless to talk about any optimal ratio of the parameters $D$ (or $D$ and $H$ ) and $h_{l}$, at which the power $P_{w}$ reaches a maximum. On the other hand, if we take into account that the dimensions of the wind wheel determine, as a rule, the power of the wind generator and, consequently, its cost, which grows both with the mast height and with the dimensions of the windmill, then from the economic point of view, the variation of the parameters determining the WEG number and dimensions, you can get quite interesting solutions that allow you to minimize the cost of the wind farm.

Average daily capacity of photovoltaic installations:

$$
P_{p}=R_{s}^{H} \cdot \eta_{s p} \cdot \eta_{p p} \cdot\left(K_{s p}(\beta) \cdot N_{p}\right) \cdot S_{s p},
$$

where $\mathrm{R}_{\mathrm{S}}^{\mathrm{H}}=\mathrm{E}_{\mathrm{S}}^{\mathrm{H}} / 24$ - average daily total solar radiation power coming to the horizontal surface of a unit area, $\mathrm{kW} / \mathrm{m}^{2} ; \eta_{s p}$ - efficiency coefficient of solar panels; $\eta_{p p}-$ efficiency coefficient of power transmission lines, communication systems, stabilization, etc. for PEC; $S_{s p}$ - the surface area of one solar panel, $\mathrm{m}^{2}$.

In expression (4), the actual area of photovoltaic panels (PEP) is actually a variable parameter. Here, the value of the area of one panel is assumed to be given. The value of the total area of all panels is determined by their number. The value of $K_{s p}(\beta)$ depends not only on the angle of the panel $\beta$ inclination but also on a number of parameters that determine the geographic position of the installation site of the solar panel, the current date and can be found in accordance with the procedure proposed in [11]. Figure 2 shows the dependence of the change in the coefficient of $K^{H}{ }_{S}$ and total solar insolation on the inclined surface $R_{S}^{H}$ for the geographic point of the terrain with coordinates: $52.98^{\circ} \mathrm{N}, 38.967^{\circ} \mathrm{E}$ (village Troekurovo, Lipetsk region, Russia). The analysis of the given dependencies allows to make an unambiguous statement about the expediency of searching for the optimal angle of the panel tilt for a given point of terrain and time period.

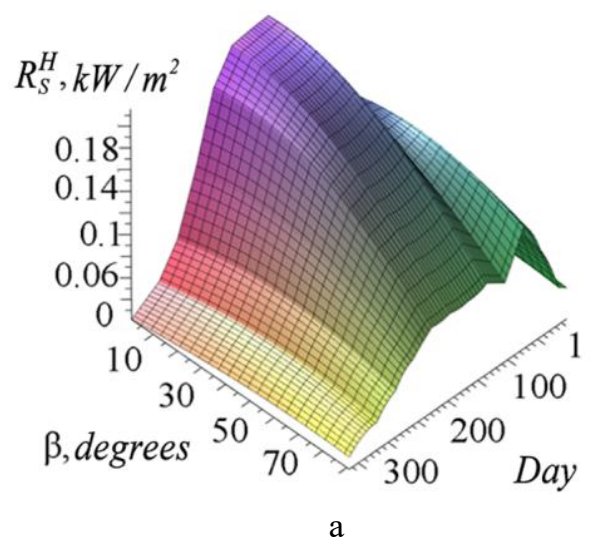

Figure 2: Characteristics of solar insolation at a geographical point with the coordinates of $52.98^{\circ} \mathrm{N}$,

$38.967^{\circ} \mathrm{E}$ : change in the coefficient $\mathrm{K}_{\mathrm{c}}(\mathrm{a})$, total insolation during the year (b), depending on the angle of inclination $\beta$ of the receiving area to the level of the horizon

In expression (4), the actual area of photovoltaic panels (PEP) is actually a variable parameter. Here, the value of the area of one panel is assumed to be given. The value of the total area of all panels is determined by their number. The value of $K_{s p}(\beta)$ depends not only on the angle of the panel $\beta$ inclination but also on a number of parameters that determine the geographic position of the installation site of the solar panel, the current date and can be found in accordance with the procedure proposed in [11]. Figure 2 shows the dependence of the change in the coefficient of $K^{H}{ }_{S}$ and total solar insolation on the inclined surface $R_{S}^{H}$ for the geographic point of the terrain with coordinates: $52.98^{\circ} \mathrm{N}, 38.967^{\circ} \mathrm{E}$ (village Troekurovo, Lipetsk region, Russia). The analysis of the given dependencies allows to make an unambiguous statement about the expediency of searching for the optimal angle of the panel tilt for a given point of terrain and time period.

The capacity of HPPs generated in the autonomous power supply system:

$$
P_{h}=\rho_{w a} \cdot g \cdot \eta_{p h} \cdot \eta_{h g} \cdot\left(Q \cdot H_{h} \cdot N_{h}\right)
$$

where $\rho_{w a}-$ water density, $\mathrm{kg} / \mathrm{m}^{3} ; g-$ acceleration of free fall, $\mathrm{m} / \mathrm{s}^{2} ; H_{h}-$ hydraulic turbine pressure, $\mathrm{m} ; Q$ - water consumption $\mathrm{m}^{3} / \mathrm{s} ; \eta_{h g}$; hydro generator efficiency coefficient; $\eta_{p h}$ - efficiency coefficient of power transmission lines, communication systems, stabilization, etc. for SHPP. 


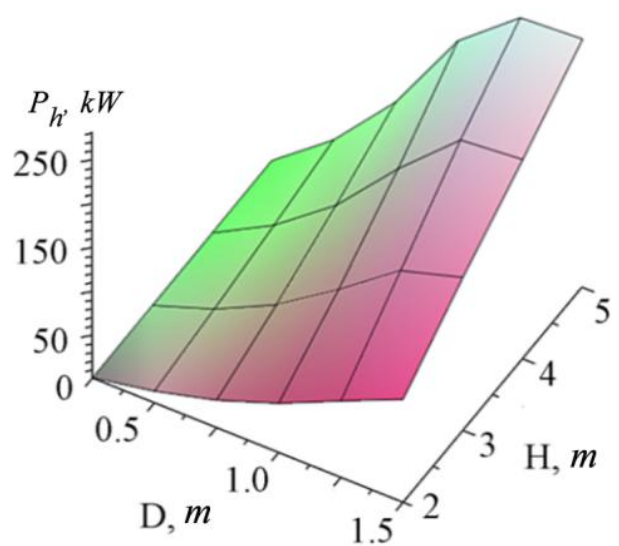

a

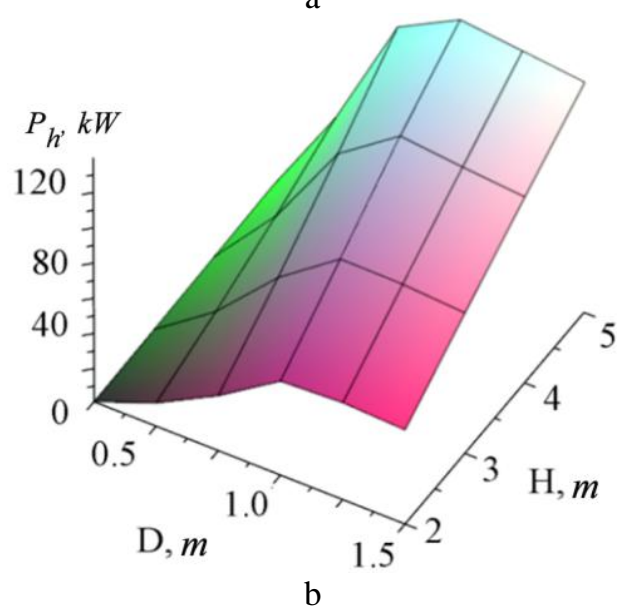

Figure 3: The dependence of the change in the turbine power of the PL10 model on its impeller diameter and the pressure head at the river flow rate of 6.4 (a) and

$$
3.2 \text { (b) } \mathrm{m}^{3} / \mathrm{s}
$$

The parameters $Q, H_{h}$ and $\eta_{p h}$ are interrelated. The nature of this relationship is determined by the design of the hydro turbine, its size and a number of other characteristics [21]. As follows from the graphs presented in Figure 3, the dependence of the power of small hydroelectric power plants (SHPP) at a given current flow of the river assumes the existence of special zones (extremes, kinks) under certain combinations of its characteristics (model, head, diameter of the impeller). In this connection, the formulation of the problem of searching for optimal characteristics of SHPPs is of undoubted interest.

As criteria for energy efficiency, we will consider:

- the maximum total capacity of the generating units of the complex $\left(\mathrm{P}_{\Sigma}\right)$ located on a given territory;

- the minimum value of the total power dissipated by the ballast resistance $\left(\mathrm{P}_{\Sigma \mathrm{b}}\right)$, if the performance condition of the generating set is fulfilled.

The choice of the first of the energy criteria as an indicator of efficiency can be used at the stage of performing work related to making decisions on the creation of autonomous enterprises (consumers) in a given territory in a particular geographical point of the terrain. The application of the second criterion is advisable in situations where the parameters of the consumer's energy costs are determined.
The total power $\mathrm{P}_{\Sigma}$ in the time interval $T$ :

$$
\begin{array}{r}
P_{\Sigma}=\frac{1}{T} \int_{0}^{T}\left(0.5 N_{w} \rho_{a} S_{w} V_{0}^{3} \eta_{W E G} \eta_{p w}+R_{s} N_{p} S_{s p} \eta_{s p} \eta_{p p}+\right. \\
\left.+0.5 N_{h} \rho_{w a} S_{h} V_{h}^{3} \eta_{h} \eta_{p h}\right) d t
\end{array}
$$

The total power dissipated by the ballast resistance $P_{b}$ in the time interval $T$ is determined by the dependence:

$$
P_{\Sigma \sigma}=\frac{1}{T} \int_{0}^{T} P_{b} d t
$$

The efficiency of an autonomous complex based on alternative energy technologies is associated with the use of not always stable sources of energy, the author proposes to introduce a safety factor $K_{s}$ to assess the safety of consumer electrical power, the value of which determines the probability of a situation when the energy supply of the consumer in full is impossible. The value of $K_{s}$ is calculated by the following formula:

$$
\begin{aligned}
& K_{s}=1-\int_{0}^{T} \frac{\Delta P}{P_{\Sigma}+P_{a}} d t, \\
& \Delta P= \begin{cases}P_{\Sigma}+P_{a}-P_{C} & \text { with } P_{\Sigma}+P_{a}-P_{C}<0 \\
0 & \text { with } P_{\Sigma}+P_{a}-P_{C} \geq 0 .\end{cases}
\end{aligned}
$$

In expression (8), $P_{a}$ is the capacity of the accumulating system, and $P_{C}$ is the power of the consumer. The accuracy of the calculations in accordance with formulas (6) - (8) will depend on the considered time interval $T$. The existing databases of meteorological observations cover a period of several decades, which guarantees a sufficiently high accuracy.

We formulate the design of an autonomous power supply system as a task of minimizing $n$ of objective functions (criteria) $F, F 2, \ldots, F n$ that are components of the n-dimensional vector $\{F\}$, whose value depends on $m$ variable parameters $X 1, X 2, \ldots, X_{m}$ or of the vector $\{X\}$ and reaches a minimum for $X=X *$. The domain of admissible values $U_{x}$ of the vector $X$ is the set of equations and inequalities connecting its components. Thus, in the general case, in order to determine the structure and parameters of an electro generating complex, we have

$$
\min _{X \in U_{x}} F(X)=F\left(X^{*}\right) .
$$

At this stage of the research, we will consider the following two variants of the problem of calculating the parameters and structure of the electro generating complex:

-We have a territory with a given configuration, area, landscape and geographical location. It is required

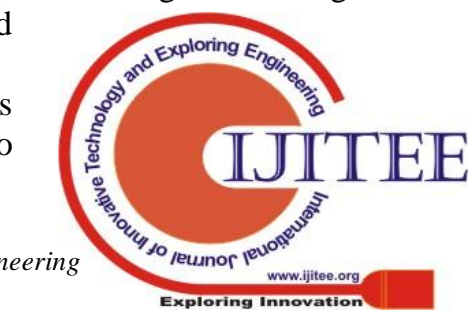


determine the structure and parameters of an autonomous power generating complex, which, at a minimum cost, generates a maximum amount of energy for a certain period of time.

- The configuration, area, terrain, geographic location of the territory of the generating complex and characteristics of consumption of energy generated by it are determined. It is required to determine the structure and parameters of an autonomous power generating complex that allows, at a minimum cost, to ensure the generation of a sufficient amount of electricity during a certain period of time.

Thus, in (9) we have a vector $\{F\}$ of dimension 2 whose components in accordance with (1):

$$
F_{1}=C_{w} \cdot N_{w}+C_{p} \cdot N_{p}+C_{h} \cdot N_{k}+C_{a} \cdot N_{a}
$$

and $F_{2}$ for the first variant in accordance with (6):

$$
\begin{aligned}
& F_{2}=\frac{T}{\int_{0}^{T}(A+B+C) d t}, \\
& A=0.5 N_{w} \rho_{w} S_{w} V_{w}^{3} \eta_{W E G} \eta_{p w}, \\
& B=R_{p} N_{p} S_{p} \eta_{s p} \eta_{p p}, \\
& C=0.5 N_{h} \rho_{w a} S_{h} V_{h}^{3} \eta_{h} \eta_{p h}
\end{aligned}
$$

and $F_{2}$ for the second variant in accordance with (7):

$$
F_{2}=\frac{T}{\int_{0}^{T} P_{b} d t}
$$

Variable parameters, components of the vector $\{X\}$, in the general case will be:

- for WEG $-N_{w}, D, h_{1}$ and $\mathrm{H}$, if the WEG is with a vertical axis (2), (3);

- for the PEC $-N_{p}(4)$; the angle of the PEC installation, as it was shown above, can be optimized, Figure 3, outside the solution of the problem (9);

- for dam hydropower plants $-N_{h}, \underline{D}, H_{h}(5)$;

- for power storage systems, this is the number of batteries connected in parallel.

Changes in the values of variable parameters are possible only within certain limits established by the characteristics of the territory of the location of the power generating complex, as well as taking into account their interconnection.

\section{Conclusion}

Thus, the working capacity of an autonomous power complex depends on the quantitative ratio of wind generators, photoelectric converters, hydroelectric generators and accumulating devices that determine its structure, and their characteristics. The parameters of the structure of the autonomous energy complex, the characteristics of the generating devices and the properties of the function of the consumer's use of energy are interrelated.

The effectiveness of the autonomous power supply system, as studies have shown, is determined by the values of two main criteria: the cost and capacity of the energy complex, as well as the value of the auxiliary characteristic - the safety factor. In accordance with expression (9), the calculation of an autonomous power supply complex is the task of multi-criteria optimization, the purpose of which is to determine its structure, characteristics of generating devices and, possibly, parameters of the function of the consumer's use of the generated energy, within the framework of a rational ratio of cost and energy indicators of generating capacities.

To realize the possibilities of computer modeling of autonomous energy complexes (AEC) built on the basis of renewable energy sources, the computer program "Alternative Energy Technologies (AET)" was developed [20], which allows both solving problems of simulation of these complexes and optimizing their structure and the parameters in accordance with (9) - (12).

\section{REFERENCES}

1. Zatsepina V.I., Zatsepin E.P., Telegin V.V., "Electricity supply of consumers using renewable energy sources", News of Higher Educational Institutions of the Chernozem Region, 2013, No 2, pp. 33-35.

2. Shkradyuk I.E, Trends in the development of renewable energy sources in Russia and the world. Moscow: WWF Russia, 2010.

3. Larin V. The state and prospects of renewable energy sources in Russia. M., 2006.

4. Cetoshnikova L.M, Non-traditional renewable energy sources. Chelyabinsk: SUSU, 2010.

5. Renewable Energy Policy Network for the 21st Century: renewables 2012 global status report, 2012.

6. Shpiganovich A.N, Telegin V.V, "Energy saving using autonomous sources on the basis of alternative energy technologies", News of higher educational institutions of the Chernozem region, 2011, No 4, p. $15-20$.

7. Telegin V.V, "Modeling of power supply systems in the joint operation of alternative and traditional energy sources", Current trends in science, technology, education, 2016, pp. 113-114.

8. Telegin V.V, Shpiganovich A.N, "Systems of autonomous power supply based on alternative energy technologies", Elektrika, 2012, No. 2, pp. 17-20.

9. Kharitonov V.P., Autonomous wind-electric installations. M: GNU VIESKH, 2006.

10. Telegin V.V, "Research of the efficiency of the autonomous power supply complex", Energy, electromechanics and energy-efficient technologies through the eyes of youth, Tomsk Polytechnical University, Vol.2, 2016, pp 202-206

11. Vissarionov V.I, Solar power engineering. M .: Publishing house MEI, 2008.

12. Alferov Zh.I., Andreev V.M, Rumyantsev V.D, "Trends and prospects of solar photovoltaics development", 2004, Volume 38, No. 8, pp. 937-948.

13. Kazhinsky B.B, Free-flow hydroelectric power stations of low power. Moscow: Gosplanizdat, 1950.

14. Kartanbaev B.A, Zhumadilov K.A, Zazulsky A.A, Guidelines for construction and operation of micro hydroelectric power stations (micro HPPs). B: "DEMI", 2011.

15. Shpiganovich A.N, Telegin V.V, "Energy flows in a closed power supply system with deep discharge batteries", News of Tula 
State University. Engineering Sciences, 2016, No. 12-3, pp. 40-46.

16. Telegin V.V., "Power Balance in the Electricity Supply System of Consumers Using Renewable Energy Sources (RES)", Actual Directions of Research in the 21st Century: Theory and Practice, 2013, No. 1, pp. 141-144.

17. Telegin V.V, "Designing of autonomous consumer power systems", Theoretical and Applied Problems of Science and Education, 2015, p. $124-125$.

18. Shpiganovich A.N, Telegin V.V, "Parameters of Optimal Power Supply Systems with Alternative Energy Sources", News of high educational establishments of Chernozemie, 2016, No 3 (45) стр. $39-43$.

19. Telegin V.V, "On the assessment of the electric potential of renewable energy sources in a given locality", Society, Modern Science and Education: Problems and Prospects, 2012, 115-117.

20. Telegin V.V, "Computer modeling of the efficiency of using alternative energy systems", Natural and Technical Sciences, 2012, No. 5 (61), pp. 309-312.

21. Krivchenko G.I. Hydraulic machines: Turbines and pumps. M .: Energia, 1978. 